\title{
Percutaneous heart valves; past, present and future
}

\author{
MM Rozeik, DJ Wheatley and T Gourlay
}

\begin{abstract}
Percutaneous heart valves provide a promising future for patients refused surgery on the grounds of significant technical challenges or high risk for complications. Since the first human intervention more than 10 years ago, over 50 different types of valves have been developed. The CoreValve and Edwards SAPIEN valves have both experienced clinical trials and the latter has gained FDA approval for implantation in patients considered inoperable. Current complications such as major vascular bleeding and stroke prevent these valves from being commonly deployed in patients considered operable in conventional surgery. This review focuses on the past and present achievements of these valves and highlights the design considerations required to progress development further. It is envisaged that with continued improvement in valve design and with increased clinical and engineering experience, percutaneous heart valve replacement may one day be a viable option for lower risk operable patients.
\end{abstract}

Keywords

Transcatheter aortic valve replacement, history, percutaneous delivery, next generation valves, future

\section{Introduction}

Treatment through transcatheter intervention can be traced back to the 1950's when a urethral catheter encasing a wire was passed through to perform a pulmonary valvulotomy. The wire was used to cut the fused commissures of the valve to free the leaflets. ${ }^{1}$ Percutaneous technologies have since been extensively used to treat other pathologies: balloon dilation has been used to perform aortic valvuloplasty or treat aortic coarctation, and more commonly, angioplasty has been employed to treat atherosclerotic obstructions. In fact the first percutaneous valve was developed in 1965 to experimentally resolve aortic regurgitation in dogs. ${ }^{2}$ An umbrella shaped valve was mounted on a catheter and inserted distally in the ascending aorta to allow blood to flow past but prevented reverse flow. Similar designs followed, including an umbrella shaped catheter mounted valve and a catheter mounted polyurethane cusp deployed percutaneously in the ascending aorta of canine models. ${ }^{3,4}$ These past valves only offered temporary relief from aortic insufficiency and were not considered long term solutions. It was the development of a heart valve by Andersen et al. in 1989 deployed percutaneously over the native leaflets which opened a window of opportunity for severe AS patients who cannot undergo surgical AVR due to comorbidities and who would have otherwise had a low chance of survival after 1-2 years following disease onset. ${ }^{5}$

Since the first human implantation in 2002, there have been over 50,000 cases of transcatheter aortic valve replacements (TAVR) in over 40 countries. Two of the most widely used valves; the Medtronic CoreValve ${ }^{\mathrm{TM}}$ prosthesis and the Edwards SAPIEN valve have both received the CE Mark of approval for commercial sale in Europe in 2007. ${ }^{6}$ Previously 
their use was limited to high risk older patients who had been refused conventional surgical AVR. However, patient selection for TAVR is shifting towards lower risk patients, the outcomes of which are currently being investigated in the PARTNER II and SURTAVI trials. $^{7}$ From an economic viewpoint, the 12-month cost of transfemoral TAVR from the Cribier Edwards PARTNER trial was found to be comparable to AVR at \$73,219 and $\$ 74,067$ respectively. ${ }^{8}$ The same study found the cost effectiveness which factored patient quality of life (QoL) to be better in $70.9 \%$ of patients with transfemoral TAVR compared to AVR, although transapical TAVR was found to be least cost effective. These delivery techniques and the existing transcatheter valves in development and clinical trials are discussed in greater detail below. With increased learning and use of a multi-disciplinary team and equipment, it is envisaged that TAVR may one day overtake surgical AVR as the gold standard treatment for aortic stenosis.

\section{First generation percutaneous heart valves}

\section{History}

Andersen et al. carried out the first study of percutaneous heart valves (PHV) on animals using a porcine aortic valve. ${ }^{5}$ The stent consisted of two wires folded about 15 times, with 3 of the folds higher than the rest to accommodate the commissures of the valve (Figure 1). The heart valve-stent assembly was then crimped onto a 3-foiled balloon dilation catheter and passed retrogradely to the descending aorta. Once the PHV was positioned over the native valve, the balloon was inflated to expand the crimped valve, flattening the native leaflets between the stent and aortic wall. Following withdrawal of the balloon, the valve immediately began to function. Wires extending from the edges of the stents allowed external fixation to the aorta.

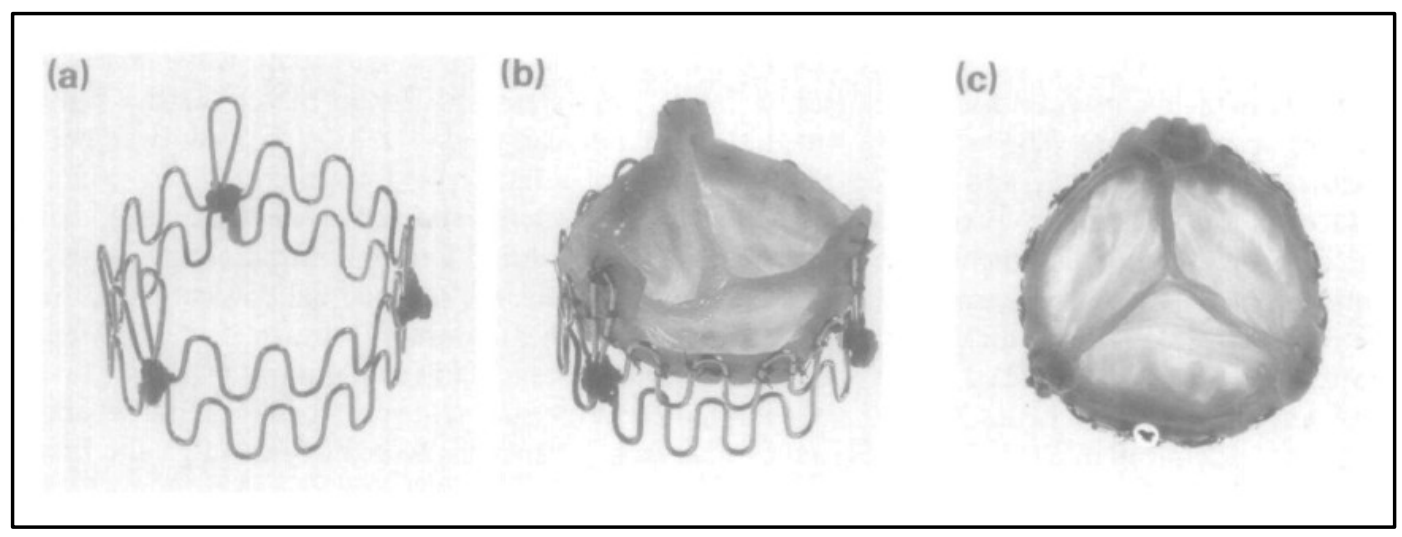

Figure 1. Percutaneous valve developed by Anderson et al. (a) stent assembly, (b) porcine aortic valve sutured to stent and (c) aortic view of valve. 
In the same year, Pavcnik et al. also conducted a percutaneous heart valve replacement on dogs using a ball and cage type design. ${ }^{9}$ In their study, a Gianturco stainless steel stent which was self-expandable was used to form a cage and a detachable latex balloon was used for the ball which was expanded by filling with either air or a pre-polymer. Once the stent-ring assembly had been deployed over the native valve, the latex balloon was then inserted into the assembly and inflated to its predetermined diameter. Following deployment, the ring was found to be successfully placed below the coronary ostia in all 12 dogs and was securely anchored by barbs. However, in three of the dogs, the ball was reported to have escaped from the cage and into the aorta. Another major setback was the non-biocompatibility of the latex ball which made it susceptible to long term degradation due to the enzymes and fatty acids in circulation.

In 2002, Boudjemline and Bonhoeffer described in more detail a PHV replacement, which they had previously developed, in 12 lambs. ${ }^{10}$ The PHV consisted of a valve from a bovine jugular vein mounted onto a platinum-iridium balloon expandable stent (Figure 2. Early percutaneous heart valves; (a) the Bonhoeffer valve $e_{78}$, (b) the Lutter valve ${ }_{12}$ and (c) the Paniagua heart valve (reprinted from Eurolntervention Vol / 1, Paniagua D, Condado J, Mejia C, Induni E, Fish R., Paniagua heart valve preclinical testing and transcatheter implantation of an aortic valve prosthesis. A9-A13, Copyright (2007), with permission from Europa Digital \& Publishing). a). ${ }^{11}$ To reduce the risk of coronary artery occlusion, space was made by dissecting the venous wall around the coronary orifices.

A problem with balloon expandable stents is the need for rapid ventricular pacing (RVP) which is necessary to prevent balloon migration but may cause hemodynamic disturbances. Lutter et al. designed a PHV taken from porcine cadavers or pericardial tissue contained within a self-expanding stent (Figure 2. Early percutaneous heart valves; (a) the Bonhoeffer valve $_{78}$, (b) the Lutter valve ${ }_{12}$ and (c) the Paniagua heart valve (reprinted from Eurolntervention Vol / 1, Paniagua D, Condado J, Mejia C, Induni E, Fish R., Paniagua heart valve preclinical testing and transcatheter implantation of an aortic valve prosthesis. A9-A13, Copyright (2007), with permission from Europa Digital \& Publishing). b). ${ }^{12}$ The stent was contained within a sheath which was unsheathed to allow the stent to expand radially within the aortic annulus. The self-expanding stent eliminates the fixed diameter issue with balloon expandable valves and enables a better fit within the aortic annulus. In 2000, Paniagua developed a percutaneous heart valve which was in vitro and animal tested prior to human implantation (Figure 2. Early percutaneous heart valves; (a) the Bonhoeffer valve ${ }_{78}$, (b) the Lutter valve ${ }_{12}$ and (c) the Paniagua heart valve (reprinted from Eurolntervention Vol / 1, Paniagua D, Condado J, Mejia C, Induni E, Fish R., Paniagua heart valve preclinical testing and transcatheter implantation of an aortic valve prosthesis. A9-A13, Copyright (2007), with permission from Europa Digital \& Publishing). c) ${ }^{13,14}$ Despite the complications in earlier valves, these studies proved that TAVR is feasible and paved the way for the next generation of heart valves; the Cribier Edwards valve and the CoreValve prosthesis. 

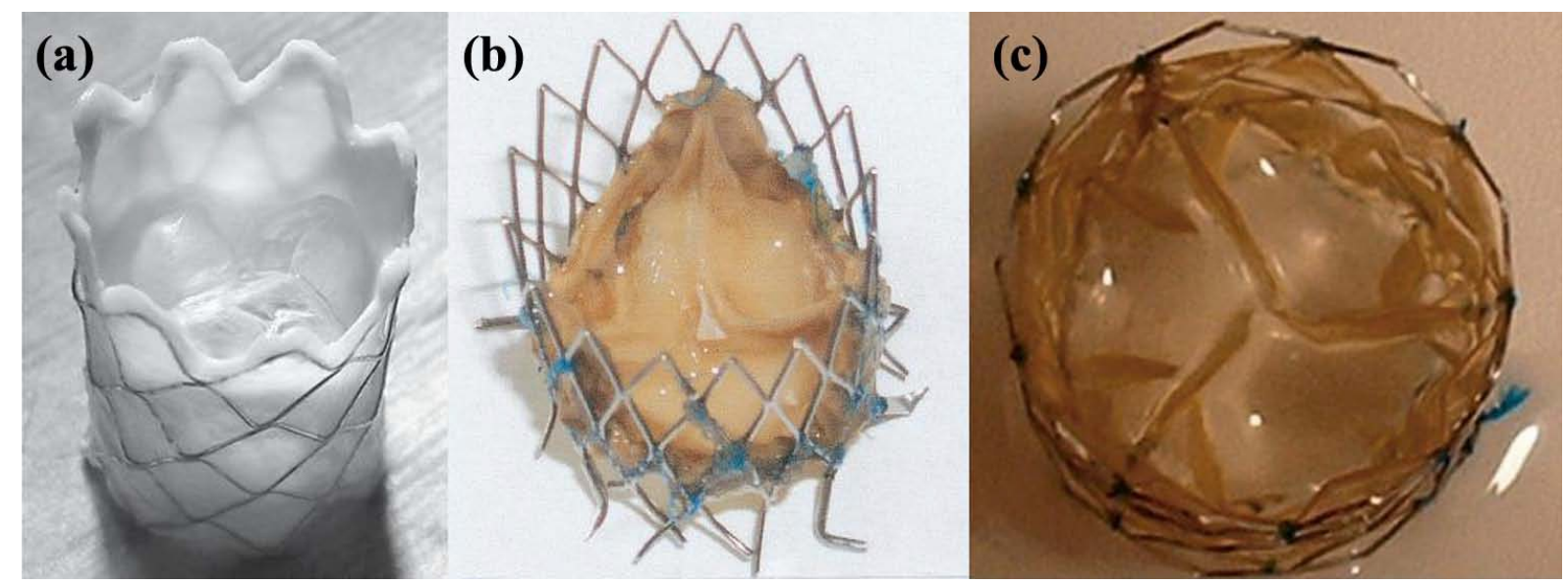

Figure 2. Early percutaneous heart valves; (a) the Bonhoeffer valve 78 , (b) the Lutter valve ${ }_{12}$ and (c) the Paniagua heart valve (reprinted from Eurolntervention Vol / 1, Paniagua D, Condado J, Mejia C, Induni E, Fish R., Paniagua heart valve preclinical testing and transcatheter implantation of an aortic valve prosthesis. A9-A13, Copyright (2007), with permission from Europa Digital \& Publishing).

Cribier Edwards valve

Professor Alain Cribier was the first to describe balloon valvuloplasty for the treatment of aortic stenosis in 1986 and also the first to implant PHV in a human in 2002. Cribier et al. implanted their balloon expandable valve into a 57 year old man. ${ }^{15}$ The patient was suffering from calcific aortic stenosis (AS), cardiogenic shock and severe leg ischemia and was declined conventional AVR by several surgeons. The authors gained ethical approval on compassionate grounds, and a PHV was inserted through a $24 \mathrm{Fr}(1 \mathrm{~mm}=3 \mathrm{Fr})$ sheath in an antegrade approach through the right femoral vein following balloon valvuloplasty of the native aortic valve. They used bovine pericardium sutured onto a short stainless steel stent which was crimped onto a balloon catheter and deployed into the native position of the aortic valve. The shorter length of the stent reduced the chance of coronary ostia occlusion, which was a problem with some of the longer stents reported by Lutter and colleagues. ${ }^{12}$ Immediately after the procedure, there was improvement in the transvalvular pressure gradient (TVG) from $30 \mathrm{mmHg}$ to $6 \mathrm{mmHg}$ and the left ventricular ejection volume increased from $14 \%$ to $17 \%$. However, the patient died 17 weeks after PHV due to non-cardiac related complications so no long term follow-up data was available.

Following success of their first human trial, Cribier et al. implanted their stent-valve into a further 6 patients, as they reported in $2004 .{ }^{16}$ Improvements were made to the stent-valve by forming the leaflets from equine pericardium (which was similar to the thickness of bovine pericardium though more compliant) and suturing them to a reinforced stainless steel tubular stent. The PHV was assembled onto a $22 \mathrm{~mm}$ or $23 \mathrm{~mm}$ diameter balloon catheter using a crimping device and advanced through a $24 \mathrm{Fr}$ sheath using the same antegrade approach as their previous study. Once positioned over the native valve, the balloon was inflated to expand the valve and flatten the native leaflets between the stent and aortic sinuses. Immediately there was an improvement in the aortic orifice area, averaging $1.7 \mathrm{~cm}^{2}$, and a decrease in the TVG in all but one of the patients. Early migration of the PHV into the ascending aorta with subsequent death occurred in this patient who presented with cardiogenic shock, associated with severe aortic stenosis and massive aortic regurgitation due 
to a previous balloon aortic valvuloplasty-induced valve tear. In all valves, there was no reported regurgitation although paravalvular leakage did occur. A post mortem on a patient who had died of non-cardiac related complications revealed calcific nodules of the native valve which were responsible for an inadequate positioning of the valve leading to paravalvular leakage.

The PHV used in the studies by Cribier et al. were produced by Percutaneous Valve Technologies which was later acquired by Edwards LifeSciences (Irvine, CA) and is now known as the Cribier-Edwards valve. ${ }^{17}$ The valve has since undergone a few design changes to drop down from a $24 \mathrm{Fr}$ to an $18 \mathrm{Fr}$ delivery profile (Figure 3 ). Initially equine pericardium was replaced with the more durable bovine pericardium to develop the Edwards-SAPIEN ${ }^{\circledR}$ valve. The stent has since been modified from stainless steel to a thinner cobalt-chromium stent with fewer struts to form the Edwards SAPIEN XT ${ }^{\circledR}$ valve. Additionally the leaflets have a scalloped shape which overall reduced the profile of the SAPIENT XT ${ }^{\circledR}$ valve. A polyester skirt sutured to the stent reduces paravalvular leakage. Edwards LifeSciences have also developed two other valves currently in early clinical trials; the SAPIEN 3 and the selfexpanding CENTERA valve.
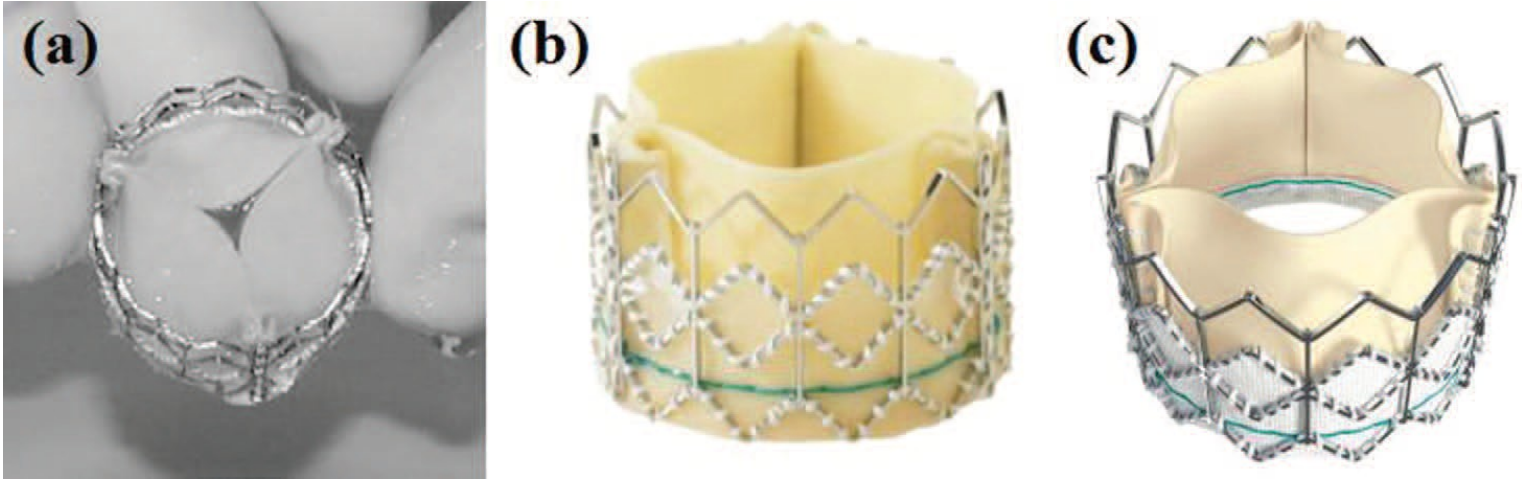

Figure 3. Evolution of the Cribier Edwards valve; (a) first generation equine pericardial valve, 16 (b) SAPIEN valve and (c) the low profile SAPIEN XT valve, both with bovine pericardium (images courtesy of Edwards LifeSciences).

In November 2011, the Edwards SAPIEN ${ }^{\circledR}$ valve was the first PHV to gain FDA approval for conventionary inoperable patients in the US. This followed results of the PARTNER trial which was the largest study to date comparing surgical AVR to TAVR. The results of this trial are discussed later on in this review. There are 4 catheter diameters; the 20 and $23 \mathrm{~mm}$ valves are housed in an $18 \mathrm{Fr}$ sheath and the $26 \mathrm{~mm}$ and $29 \mathrm{~mm}$ valves are housed in a $19 \mathrm{Fr}$ and $22 \mathrm{Fr}$ sheath respectively. ${ }^{19}$ They are suitable for native annuli diameters ranging from 16-27 mm. An expandable sheath known as the eSHEATH ${ }^{\circledR}$ which is currently only available in Europe and Canada enabled reduced delivery profiles of $16 \mathrm{Fr}, 18 \mathrm{Fr}$ and $20 \mathrm{Fr}$ to be feasible. They expand only when the valve is passed through and collapse back to their reduced diameter, thereby reducing the time the arteries are exposed to large strains. These sheaths allow for an acceptable minimal iliofemoral arterial diameter of 6, 6.5 and $7 \mathrm{~mm}$ respectively. ${ }^{20}$

\section{CoreValve prosthesis}


Grube et al. reported on a study that involved a PHV known as the CoreValve (Medtronic Inc., Minneapolis, USA), which was made from porcine pericardium sutured onto a selfexpanding nitinol stent. ${ }^{21}$ Porcine is considerably thinner (typically $200 \mu \mathrm{m}$ thick) and stiffer than both bovine and equine pericardium. The nitinol material is a shape memory alloy of nickel and titanium which has the ability to deform at low temperatures but regain its original shape at body temperature. The CoreValve stent was designed so that the proximal end had a larger diameter than the distal end, allowing secure fixation onto the ascending aorta. The middle of the stent was also slightly narrowed to prevent occlusion of the coronary ostia.

Extracorporeal circulation through the left common femoral artery and vein was employed for hemodynamic support during the PHV deployment, although RVP could have also been used. $^{21}$ The overall valve stent assembly was inserted into a $24 \mathrm{Fr}$ catheter sheath which was advanced through the left common iliac artery via a retrograde approach over the native aortic valve. Once the correct position was asserted, the sheath was withdrawn, deploying the self-expanding valve.

In a later study by the same group, the sheath was brought down to an $18 \mathrm{Fr}$ size. ${ }^{22}$ In their study, a comparison was made between delivery of the second generation device $(21 \mathrm{Fr})$ and the third generation device (18 Fr). Their results showed a significant improvement in the 18 Fr catheters compared with the $21 \mathrm{Fr}$ catheters which led to a time reduction of $148 \pm 50 \mathrm{~min}$ compared to $188 \pm 55$ min respectively. $64 \%$ of patients with the $18 \mathrm{Fr}$ catheters did not require extracorporeal support whereas all patients with the $21 \mathrm{Fr}$ catheters did. Moreover, $42 \%$ of patients with the $18 \mathrm{Fr}$ catheters did not require a surgical cut down of the access vessel and $25 \%$ of the $18 \mathrm{Fr}$ catheters only needed local anaesthesia of the groin compared to none in the $21 \mathrm{Fr}$ group, who required general anaesthesia. In a large single trial study by Grube et al. procedural success rates improved from $70.0 \%$ in the first generation valves to $91.2 \%$ in the third generation valves. ${ }^{23}$ The study also highlighted the high incidence of atrioventricular (AV) block occurring in PHV procedures compared with surgery. A higher incidence of patients fitted with a pacemaker was reported in the $18 \mathrm{Fr}$ valve, although this was attributed to a change in policy to provide a 48 hour temporary pacemaker fitting. The CoreValve is available in 3 sizes; $26 \mathrm{~mm}, 29 \mathrm{~mm}$ and $31 \mathrm{~mm}$ and accommodate native annular diameters of $20-29 \mathrm{~mm}^{20}$ 


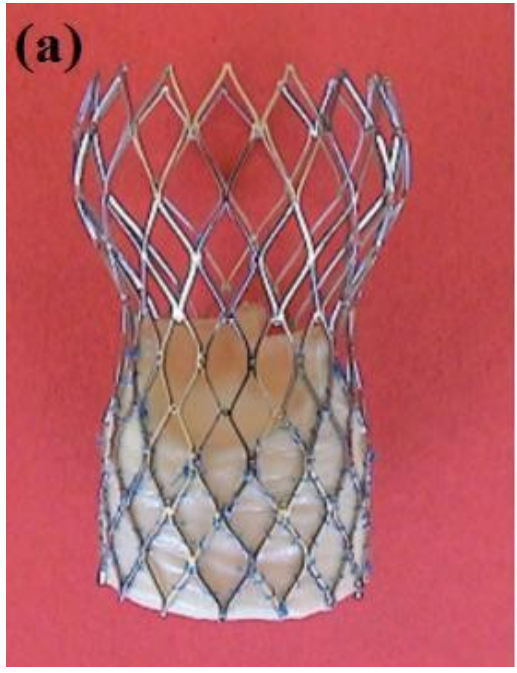

(b)

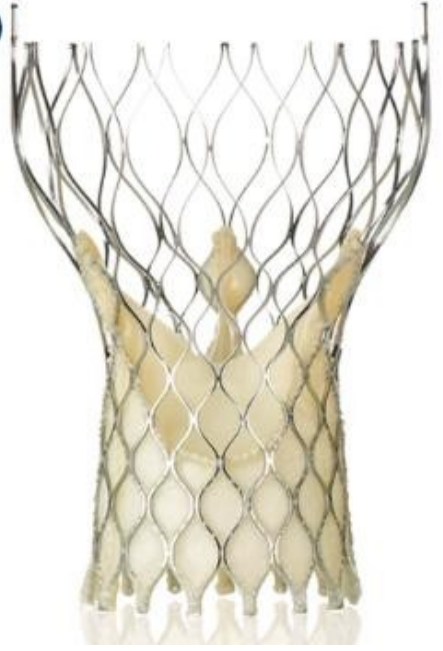

(c)

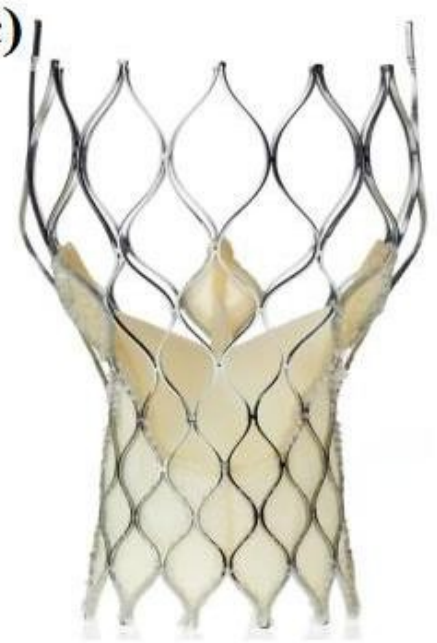

Figure 4. (a) First ${ }^{21}$ and (b) Third generation of the CoreValve ${ }^{\circledast}$ prosthesis and (c) CoreValve ${ }^{\circledast}$ EvolutTM prosthesis, (images with the courtesy of Medtronic).

\section{Transcatheter approaches}

\section{Clinical evaluation and imaging}

Following over 50,000 procedures, TAVR is currently recommended to be performed only in cardiology and cardiac surgery centres. This enables procedures to be quickly transferred to surgery in the case of complications. A hybrid approach consisting of a multi-disciplinary team of clinical cardiologists, interventionists, surgeons, anaesthetists and imaging specialists are involved in the technical process and pre- and post-procedural patient care and evaluation. $^{24}$

Two scoring systems have been used in the past to assist in determining patient eligibility and predict mortality rates for TAVR; the logistic EuroSCORE I and the Society of Thoracic Surgeons Predicted Risk of Mortality (STS PROM). However, recent outcomes from trials have highlighted the need for better predictive scoring systems which would factor frailty and comorbidities such as coronary arterial disease and congenital bicuspid valves which may contraindicate TAVR. ${ }^{25-27}$ Updated surgical risk algorithms such as the logistic EuroSCORE II and STS are expected to provide a better predictive mortality rate in high risk patients. ${ }^{20}$ Additionally, the success of AVR in older patients depends on the skill of the surgical centre rather than age alone and therefore TAVR should be compared with results from highly skilled surgeons rather than depend on the risk scores. ${ }^{28}$

As TAVR is largely non-invasive, correct imaging of the aorta, its valvular complex, the left ventricle and the arterial vasculature is of utmost importance in helping determine the route to adopt and prosthesis sizing. Additionally, the team needs to be able to visualise deployment in order to avoid complications such as stent migration or incorrect positioning. This involves a combination of echocardiography, right and left heart catheterization, left ventriculography, 
supra-aortic angiography, and coronary angiography. ${ }^{29}$ The arterial vasculature is imaged using angiography to determine the feasibility of a transfemoral approach. Tortuosity is not necessarily a contra-indication to iliofemoral arterial access since patients with healthy albeit tortuous arteries can still undergo transfemoral-TAVR, whereas patients with larger but heavily sclerotic arteries may not be suitable candidates. Although there are no clinical indications as to which transcatheter approach is superior, a 'transfemoral first' decision is usually adopted before considering other methods.

Imaging of the aortic annulus has generally been performed through either the use of transthoracic (TTE) or and transesophageal echocardiography (TEE). TEE in particular has been favoured for accurate imaging when performing a transapical TAVR due to the close proximity of the TEE probe to the aorta. The general shape of the aortic annulus and LVOT is elliptical and two-dimensional echocardiography may not be able to correctly determine the largest annulus size. Three-dimensional TEE has been found to be measure a larger annulus diameter and be more likely to correctly predict the final prosthesis size compared to 2D TEE. ${ }^{30,31} \mathrm{Ng}$ et al., however, found that both $2 \mathrm{D}$ and 3D TEE significantly underestimated the annular area by $16.4 \%$ and $12.9 \%$ respectively, when compared with multi-slice computed tomography (MSCT). ${ }^{32}$ Similar findings have also been reported with other authors. ${ }^{33,34}$ Underestimation of the EOA can lead to a patient-prosthetic mismatch (PPM) and imaging may be better suited to three-dimensional analysis using MSCT or magnetic resonance imaging.

\section{Antegrade transseptal approach}

The antegrade transseptal approach reported by Cribier et al. involves access through the right femoral vein, an atrial transseptal entry, through the mitral valve into the aortic annulus. ${ }^{15,16}$ Initially a stiff guide-wire is advanced from the right femoral vein through the interatrial septum to the descending aorta and externalized through the left femoral artery. A stented valve crimped over a $24 \mathrm{Fr}$ balloon catheter is advanced through the guide wire and deployed over the native leaflets. Rapid pacing of the right ventricle is used to decrease aortic blood flow during valve deployment. This approach enables large stent mounted catheters to be used and would also allow a more precise placement of the prosthesis as there is less motion of the large delivery system during the cardiac cycle. Additionally, the antegrade approach enables the valve to bypass the calcific side of the native leaflets. However, this approach is technically challenging and prone to complications due to the close proximity of the mitral valve. The procedure has been largely dropped in favour of the retrograde approach through the femoral arteries.

\section{Transfemoral retrograde approach}

Panigua et al. were the first to report a clinical case in 2003 with the retrograde approach, of a valve with a collapsed profile of $2 \mathrm{~mm}$ and a $12-16 \mathrm{Fr}$ introducer shield. ${ }^{35}$ Due to the low profile of their valve, they were able to deliver it in a 62 year old man through the right femoral artery, the abdominal aorta and the left ventricle. The TVG dropped to $<5 \mathrm{mmHg}$ 
and cardiac output increased from $1 \mathrm{~L} / \mathrm{min}$ to $5 \mathrm{~L} / \mathrm{min}$. Although the patient died 5 days later due to biventricular failure and refractory hypotension, valve function was deemed satisfactory following echo-Doppler evaluation. At that time, other PHVs including the first generation CoreValve ${ }^{\mathrm{TM}}$ reported use of the transfemoral TAVR (TF-AVR) with favourable outcomes. $^{21,36,37}$ This approach became increasingly more popular following reduction in sheath sizes of the next generation PHVs.

The general procedure for TF-AVR involves a surgical cut down or a puncture for a fully percutaneous access to the common femoral artery. Depending on the protocol practised in the centre, the patient is given either a general or local anaesthetic and mildly sedated. TEE, fluoroscopy and aortography are commonly adopted to visualise the vasculature and provide guidance during valve deployment. ${ }^{38}$ Initially a guide wire is passed through from the femoral artery to the aorta which is then exchanged for an extra stiff 0.035 " guide-wire. A balloon catheter is passed through to pre-dilate the valve. RVP of the right ventricle at approximately $200 \mathrm{bpm}$ is performed to reduce aortic flow and prevent distal migration of the balloon. An introducer sheath is inserted into the femoral artery and the PHV and catheter assembly are then advanced through the sheath to the descending aorta and over the native valve. Once in the correct position, the valve is unsheathed to enable the stent to self-expand or a balloon is used to expand the valve which begins functioning immediately. RVP is again practised in balloon expandable valves and should only be carried out once blood pressure has returned to normal following disrupted hemodynamics from previous pacing. The introduction of steerable delivery catheters such as the Retroflex and Novaflex catheters developed by Edwards LifeSciences made the retrograde approach more feasible (Figure 5).

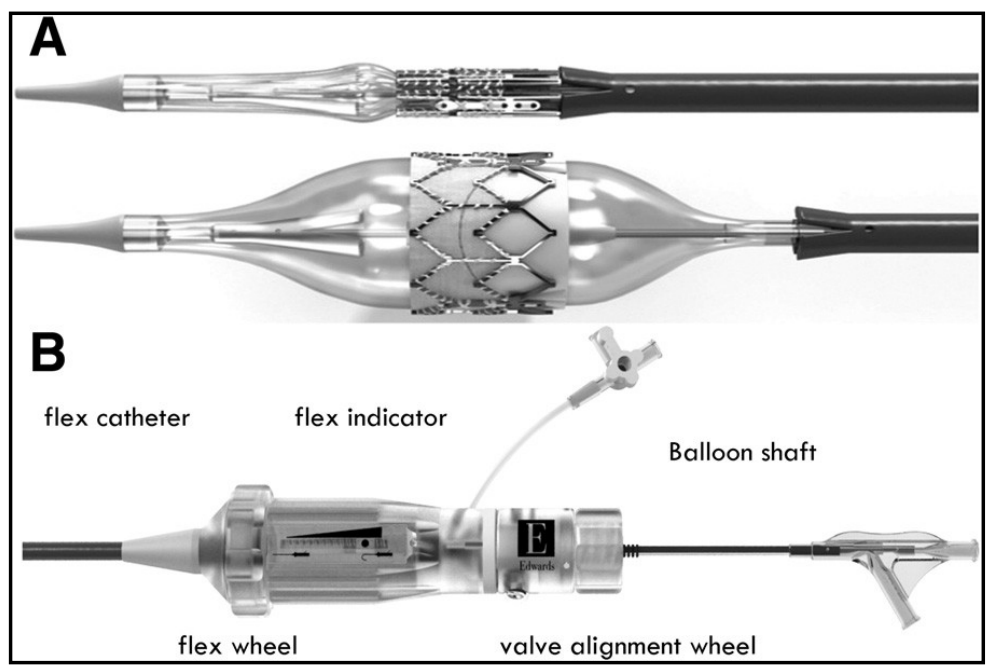

Figure 2. Edwards SAPIEN XT delivery; (A) Novaflex balloon catheter in collapsed and expanded state and (B) the Novaflex handle. ${ }^{39}$ 
First generation PHV required sheaths as large as $24 \mathrm{Fr}$ which could lead to major vascular complications particularly in iliofemoral tortuous arteries. However with the introduction of lower 16-18 Fr delivery profiles, incidence of this complication is expected to decrease. An $18 \mathrm{Fr}$ catheter would enable easy delivery through femoral arteries as small as 6-7 mm compared with the $8-9 \mathrm{~mm}$ artery diameter needed with the $21 \mathrm{Fr}$ catheters. The smaller catheter size would also be a suitable candidate for younger patients and females who generally have smaller femoral arteries. ${ }^{40}$ However the retrograde approach would still be unsuitable for patients with femoral or iliac artery disease in which the arteries could be tortuous or in heavily calcified arteries, making a percutaneous delivery difficult.

\section{Transapical aortic intervention}

In 2006, Lichtenstein et al. were the first to describe an approach in which the aortic valve was delivered through the apex of the left ventricle without needing cardiopulmonary bypass. ${ }^{41}$ They used a Cribier-Edwards balloon expandable valve via a $24 \mathrm{Fr}$ sheath in 7 patients and reported favourable results, with an improvement in median area from $0.7 \mathrm{~cm}^{2}$ to $1.8 \mathrm{~cm}^{2}$ post procedure and $1.6 \mathrm{~cm}^{2}$ at 1 month follow up. Paravalvular leakage was reported to be a common complication although it was not considered to be clinically significant. The authors also noted that potential complications of this procedure could include myocardial perforation and mitral valve or aortic valve damage.

The transapical aortic valve replacement (TA-AVR) involves making a cut at the $5^{\text {th }}$ or $6^{\text {th }}$ intercostal space to expose the left ventricular apex. A superstiff guidewire is passed antegradely through a puncture in the apex, through the aortic valve and into the ascending aorta. After a pre-dilation with a balloon valvuloplasty, the sheath containing the valve is then advanced through the apex to the aortic valve using the guidewire to manipulate the valve to the correct position. ${ }^{42}$ With the Edwards SAPIEN valve, expansion is held for 5 seconds under RVP. Over-sizing of the prosthesis and moderate over-dilating can reduce the risk of paravalvular leakage and is frequently practised. Excessive dilation can lead to regurgitation and inadequate leaflet coaptation. ${ }^{41}$

A study was carried out on 71 patients who underwent TA-AVR with a Cribier Edwards valve having been turned down for surgical replacement and percutaneous TF-AVR. Mortality after 30 days was $16.9 \%, 33 \%$ of which occurred in the first 15 patients which suggests a learning curve with this approach. ${ }^{43}$ In another study, the TA approach was evaluated in 299 patients who were divided into an early experience and recent experience group which were conducted pre- and post $\mathrm{CE}$ approval of TA aortic valve intervention. ${ }^{44} \mathrm{In}$ their study, 30-day mortality rate was lower in the latter group. Results from the SOURCE registry have demonstrated that TA-AVR has similar procedural success rates to TF-AVR (92.7\% vs. $95.2 \%)$. TF-AVR had a higher survival rate at 1 year $(81.1 \%$ vs. $72.1 \%)$, however patients enrolled for a TA-AVR had more comorbidities and a higher baseline EuroSCORE. ${ }^{45}$ 
Valves designed especially for a TA-AVR approach have been developed and are undergoing clinical trials. The Symetis Acurate $\mathrm{TA}^{\mathrm{TM}}$ valve includes a porcine heart valve sutured to a nitinol stent with a Dacron skirt which has been found to reduce paravalvular leakage (Figure $6 a)$. It is unsheathed in the ventricle through a two-step implantation procedure. This valve was tested in 40 high risk patients with survival rates of $87.5 \%$ and $82.5 \%$ at 30 days and 6 months follow-up. ${ }^{46,47}$ The Engager ${ }^{\mathrm{TM}}$ valve has scalloped bovine pericardial leaflets sutured to a self-expanding nitinol stent (Figure 6b). The stent has a support frame which clips over the native leaflets and a polyester skirt which seats at the base of the sinuses. The JenaValve ${ }^{\mathrm{TM}}$ consists of a porcine aortic valve sutured to a nitinol stent with a feeler to guide positioning and a clip which fits over the native leaflet (Figure 6c). During release of the JenaValve ${ }^{\mathrm{TM}}$, the sheath is partially retracted to release the feelers and enable correct anatomical positioning such as commissural alignment. The prosthesis then expands at the proximal end but remains connected at the distal end, enabling it to be retrieved and repositioned if necessary. This implantation procedure enables TA-AVR to be carried out without the need for RVP.

\section{Other transcatheter approaches}

Other approaches have been adopted including trans-aortic, -subclavian and -axillary, all of which enable bypass of the femoral arteries, enabling larger catheter sheaths to be used at a shorter distance. The trans-aortic approach is performed through a right anterior thoracotomy or a partial upper J- or T- shaped median sternotomy and has been used with both the CoreValve and Edwards valves. Trans-subclavian and trans-axillary approaches require a surgical cut-down to isolate the respective arteries. The trans-subclavian approach can lead to serious and life threatening complications, giving the trans-axillary approach an advantage in that its occlusion could be compensated through other arteries.

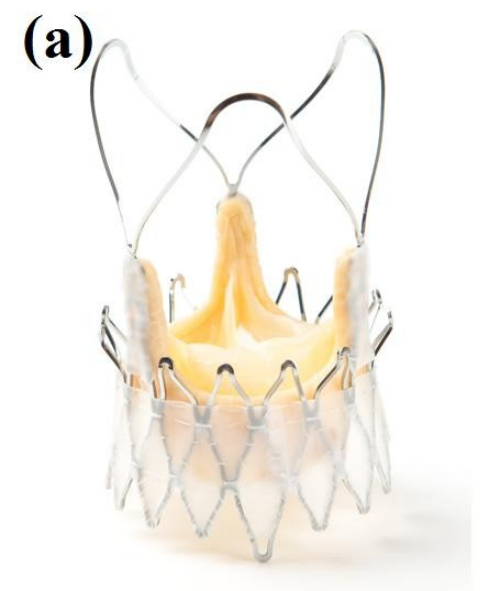

(b)

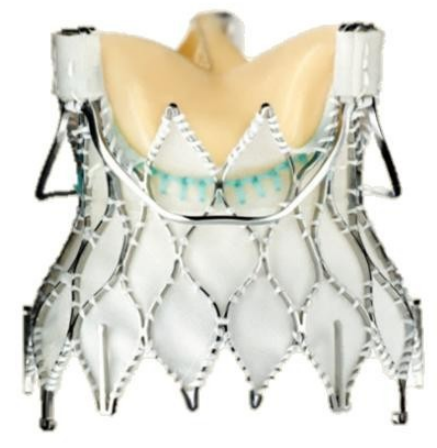

(c)

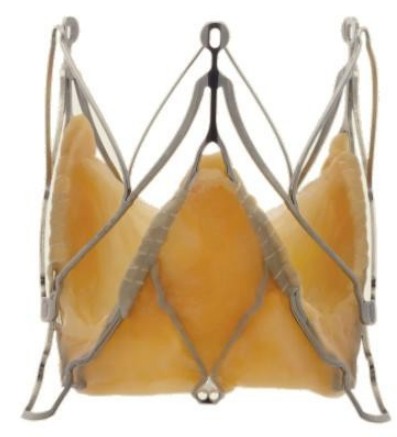

Figure 3. Transapical Valves; (a) Symetis Acurate ${ }^{\mathrm{TM}}$, (b) Medronic Engager and (c) $2^{\text {nd }}$ Generation JenaValve. ${ }^{48}$ 


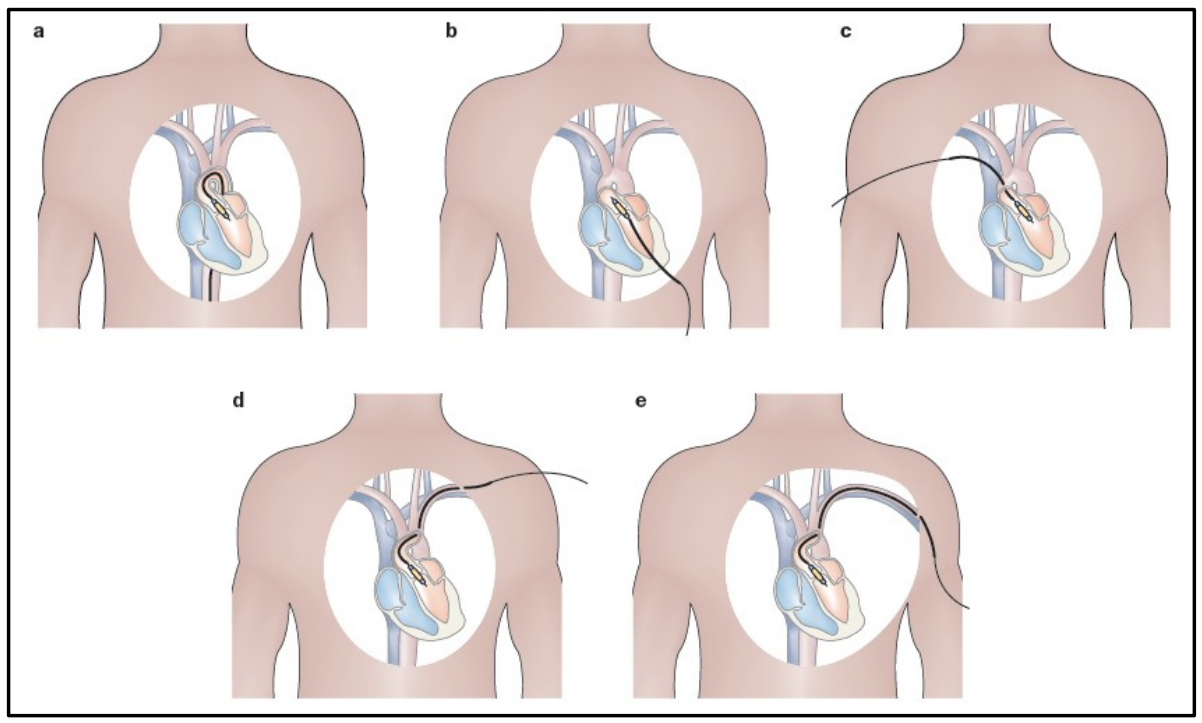

Figure 4. Transcatheter approaches a) Retrograde transfemoral approach, b) Antegrade transseptal approach, (c) trans-aortic approach, (d) trans-subclavian artery and (e) trans-axillary approach. ${ }^{19}$

\section{Repositionable and retrievable percutaneous heart valves}

The main problem with the first generation valves were that once deployed they could not be repositioned or retrieved. Correct valvular alignment and positioning has already been indicated from trial outcomes to be a necessity to reduce incidence of paravalvular leakage and obstruction of the coronary ostia. Additionally, it could lead to other complications including stent migration, fracture and mitral regurgitation. As such, it is desirable to have a valve which could be fully retrieved and repositioned in cases where a valve has been deployed in a suboptimal position.

The second and third generation CoreValve prosthesis had the ability to be fully retrievable after two thirds of the prosthesis had been deployed. However, the first fully repositionable PHV was the Sadra Medical self-expanding Lotus ${ }^{\mathrm{TM}}$ Valve prosthesis reported in a patient study by Buellesfeld et al. ${ }^{49}$ The valve (Figure 5) consisted of a bovine pericardial tissue sutured onto a braided nitinol stent which had a similar design concept to the "Chinese Finger Trap" principle. ${ }^{48}$ During delivery in a 21 Fr sheath, the stent undertook a longitudinal and narrowed shape which, when unsheathed, shrank in length and expanded radially outwards. This created a high radial force and reduced the risk of coronary ostia occlusion. The prosthesis also incorporated a self-locking mechanism, which allowed the entire valve to be retrieved and repositioned as necessary by unlocking it. 


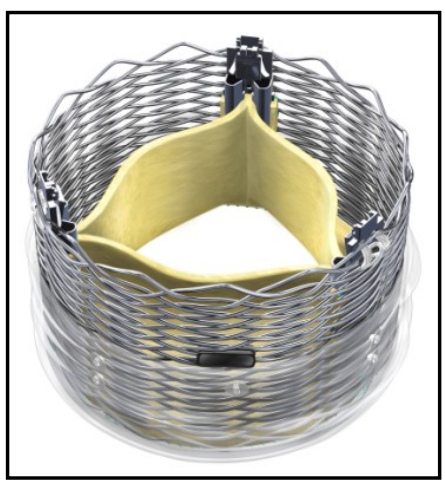

Figure 5. The Lotus ${ }^{\mathrm{TM}}$ heart valve is a bovine pericardial valve sutured onto a braided self-expandable stent, shown with the stent expanded and shortened.

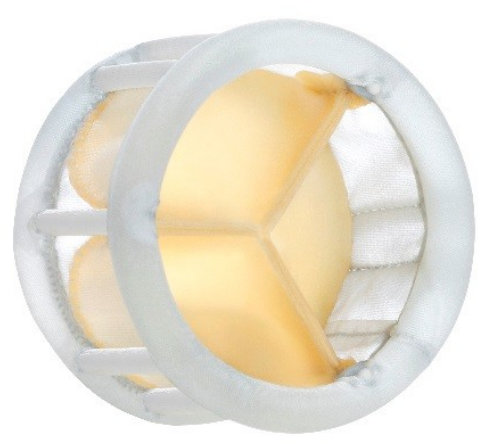

Figure 6. The Direct Flow Medical valve (Image courtesy of Direct Flow Medical Inc.)

The Direct Flow Medical (DFM) heart valve consists of a bovine pericardial tissue tri-leaflet valve within a sheathed delivery system (Figure 6). The leaflets are treated with anticalcification and sutured into inflatable Dacron cuffs which create a tight seal and reduce paravalvular leakage. ${ }^{50}$ Once the position of the valve is determined, the aortic and ventricular cuffs are inflated for fixation into the aortic annulus. These cuffs are inflated with either air or a contrast and saline solution which are then exchanged with a proprietary inflation medium (IM) whilst maintaining pressure to keep the valve expanded. The IM gel achieves $95 \%$ of its final hardness within hours. ${ }^{50}$ The delivery system consists of a $15 \mathrm{Fr}$ multi-lumen catheter, and the implant is housed in the distal end which is $22 \mathrm{Fr}$ in size. Three position/fill lumens (PFL's) are incorporated into the catheter which enabled the cuffs to inflate and deflate accordingly and for guiding and aligning the implant within the annulus.

Temporary placement studies of the DFM valve by Low et al. noted that the $14 \mathrm{~mm}$ height of the PHV was too short to accommodate the cusps of the native valve which led to a high transvalvular pressure gradient post implantation. ${ }^{51}$ This led to a design modification to increase the height to $16 \mathrm{~mm}$ and $17 \mathrm{~mm}$ in the $23 \mathrm{~mm}$ and $25 \mathrm{~mm}$ valves respectively, without compromising the coronary ostia. Overall, there was a drop in transvalvular gradient from a mean pressure of $87.6 \mathrm{mmHg}$ pre-implantation to $17.9 \mathrm{mmHg}$ post-implantation and no aortic insufficiency was evident in 7 of the patients, demonstrating excellent hemodynamics of the valve. 
In an another study in $16 \mathrm{AS}$ patients deemed too high risk for surgery, there were improvements in mean transvalvular gradient from $50.1 \mathrm{mmHg}$ to $19.6 \mathrm{mmHg}$ after 30 days. Additionally, the aortic valve area increased from a baseline value of $0.57 \mathrm{~cm}^{2}$ to $1.47 \mathrm{~cm}^{2}$ Survival rates with the DFM valve after 1 and 2 years were $81 \%$ and $69 \%$ respectively. ${ }^{52}$

\section{Valve-in-valve procedures}

In 2005, a CoreValve prosthesis which was implanted in a 58 year old woman was incorrectly placed in a sub-annular position leading to severe AR through the stent struts and impingement of the anterior leaflet of the mitral valve. Due to the patient's refusal to undergo surgery, another CoreValve was deployed over the first valve in the correct position. A 3 year follow-up showed a reduction in a NYHA functional class of IV to II. This case was the first to report the feasibility of a valve-in-valve procedure. Following this, cases in patients with degenerated bio-prosthetic valves receiving a percutaneous valve have been reported. ${ }^{53,54}$ The ability to implant a valve over an existing prosthesis creates an opportunity for patients undergoing a re-replacement with a bio-prosthetic valve to be enrolled for a PHV case. ${ }^{55}$ Valve -in-valve procedures have also found an advantage in reducing paravalvular regurgitation due to PPM or incorrect placement of the initial PHV. ${ }^{56}$ Additionally this technique would be most beneficial in younger patients who would have otherwise required repeat surgical AVR procedures in their lifetime. However, repeated valve-in-valve procedures should be limited as they may affect the hemodynamics such as by decreasing the EOA or increasing the TVG.

\section{Results from the PARTNER trial}

In 2007, Edwards Lifesciences enrolled patients in the PARTNER (Placement of Aortic Transcatheter Valves) trial to investigate the effectiveness and safety of TAVR using the Edwards SAPIEN valve. Cohort A involved 699 AS patients who were considered surgical candidates for valve replacement. They were randomly assigned to undergo either the TAVR with the Edwards SAPIEN valve or surgical AVR ${ }^{57}$ Of those that underwent TAVR, the patients were divided into having either a TF- or TA-AVR procedure depending on whether they could accommodate the 22 Fr or 24 Fr sheaths. Cohort B consisted of 358 AS patients who were considered unsuitable for surgery and were randomised into either having TAVR or non-surgical treatment. ${ }^{58}$ Of those who underwent therapy; $68 \%$ had balloon valvuloplasty, $6.7 \%$ underwent surgical AVR, $2.8 \%$ had an apicoaortic conduit fitted as well as AVR and $2.2 \%$ underwent TAVR outside the United States at a non-participating site.

There was no significant difference in the mortality rate between the TAVR group and the surgical group after 30 days and one year and this difference remained insignificant after two 
years at $33.9 \%$ compared to $35 \%$ respectively. Additionally, the rates of stroke or transient ischemic attacks after two years were higher in the TAVR group at $11.2 \%$ compared to $6.5 \%$ in the surgical group although this difference was not statistically significant. TAVR however had significantly $(p<0.001)$ higher rates of major vascular complications $(11.6 \%$ vs. $3.8 \%)$ whereas AVR had a significantly $(\mathrm{p}=0.002)$ higher incidence of major bleeding $(29.5 \% \mathrm{vs}$. $19.0 \%)^{41,59}$

In the Cohort B study, the rates of mortality from any cause after one and two years respectively were $30.7 \%$ and $43.3 \%$ in the TAVR group compared to $50.7 \%$ and $68.0 \%$ in the non-surgical group. The rate of stroke remained significantly $(\mathrm{p}=0.01)$ higher after two years in the TAVR group at $13.8 \%$ compared to $5.5 \%$ in the non surgical group. However, patient rehospitalisation after two years was significantly higher $(\mathrm{p}<0.001)$ in the non-surgical group at $72.5 \%$ compared to $35 \%$ in the TAVR group. ${ }^{58,60}$

The major vascular complications reported with the use of the valves may be a result of the large femoral (24 Fr) sheaths that are used to access the femoral arteries. These results indicate the need for a reduced delivery profile and support frame which will enable patients with smaller illiofemoral arteries to benefit from a TAVR procedure. ${ }^{58}$ MRI studies have indicated cerebral embolism likely due to dislodged calcific debris from the aortic valve in many TAVR patients which may be the cause for the higher incidence of stroke. ${ }^{61}$ Other causes of stroke may be due to hypotension from RVP or hemodynamic instability during the procedure. $^{62}$

Cao et al. conducted a meta-analysis from 14 studies of the differences between transcatheter aortic valve implantation and aortic valve replacement for severe aortic stenosis in high risk but operable patients. Three of the studies reported outcomes from two randomized controlled trials (Cohort A of the PARTNER trial) and the remaining 11 were observational studies. The results indicated no significant differences between TAVR and AVR in stroke, all-cause mortality and cardio-vascular caused mortality during the peri-procedural period, at 12 months and beyond 12 months. However, in a subgroup analysis of the two randomized controlled trials, TAVR had a significantly higher incidence of stroke and transient ischemic attacks. In other peri-procedural outcomes from the meta-analysis, TAVR had a significantly higher incidence of vascular complications and permanent pacemaker insertion and a significantly lower incidence of major bleeding compared to AVR. Severe or moderate paravalvular and transvalvular regurgitation was also significantly higher in TAVR patients compared to AVR. The authors highlighted the challenge faced in comparing TAVR to AVR due to different inclusion and exclusion criteria and suggest future studies should adhere to the Valve Academic Research Consortium (VARC) standardized endpoint definitions. ${ }^{63}$

\section{Complications}


There are several challenges still to overcome with a TAVR procedure. The rate of stroke following TAVR has been relatively high (3-9\%) and AV-Block is also commonly reported in $4-8 \%$ of cases. ${ }^{64}$ A higher incidence of new pacemakers fitted is reported with the CoreValve prosthesis due to the close proximity of the prosthesis to the AV conduction bundles. ${ }^{65-67}$ Major vascular complications are still commonly reported, having an incidence rate of $10-15 \%$ with the retrograde TAVR cases which, is largely due to the size of the introducer sheaths. In a patient population study by Toggweiler et al., arterial diameters which were smaller than the external sheath diameter were found to increase the chances of vascular complications and unplanned surgery. ${ }^{68}$ The study also found that when smaller 18 $19 \mathrm{~F}$ sheaths were used, the prevalence of vascular complications decreased from $32 \%$ to $9 \%$. The complications also decreased as a result of improved valvular closure techniques and percutaneous management. It is clearly evident that a reduced profile is necessary to overcome the vascular complications commonly reported. Furthermore, a reduced profile would increase the flexibility of the delivery system which would improve angular movement within the aortic root and LVOT.

As the percutaneous valve is designed to be deployed over the calcified native valve, there is a real risk of emboli from the friable valve, which could cause coronary occlusion or stroke. A high incidence of this is reported in the CoreValve prosthesis which may be due to the incomplete entrapment of the friable native leaflets in the narrowed portion of the stent. Percutaneous embolic protection devices to capture loose emboli have been developed and their use could reduce incidence of stroke. It is also worth noting that the calcified leaflets are pushed away from the flow boundary and as such the calcium may begin to be reabsorbed due to a lack of shear stress. ${ }^{41}$ In such an event, implant loosening or migration may occur. This would be more problematic with balloon expandable valves than self-expanding valves.

RVP is necessary in FT-AVR using balloon devices to prevent migration of the balloon with pulsatile blood flow. However their use can lead to disturbances in hemodynamics which can lead to other complications. Grube et al. carried out a pivotal study which involved implanting the CoreValve prosthesis without balloon pre-dilation, thereby eliminating the need for RVP altogether. ${ }^{69}$ Although post-dilation was required in 10 of the 60 patients, their study demonstrated the feasibility and safety of not pre-dilating self-expanding valves and may simplify future TAVR procedures. TAVR generally remains unsuitable for patients with aortic regurgitation, particularly in cases where comorbidities such as aortic dilation and dissection exist. The exception to this is the second generation JenaValve which received CE Mark approval in 2013 for treatment of aortic insufficiency, having been approved in 2011 for transapical delivery for the treatment of aortic stenosis. The success of this technology is attributed to the valves clip mechanism which allows fixation on the native leaflets in the absence of calcification. ${ }^{70,71}$

Paravalvular, intra-prosthetic or combined regurgitation is relatively high with TAVR which may be caused by PPM, incomplete expansion, incorrect site of implantation, a bicuspid valve or due to asymmetric calcification of the cusps. ${ }^{56}$ Several studies have found moderate to severe paravalvular leakage to correlate with late mortality. ${ }^{59,72,73}$ In a study by Sinning et al., an aortic regurgitation index less than 25 (calculated as the ratio of the gradient between the diastolic blood pressure and left ventricular end diastolic pressure to systolic pressure) significantly increased 1 year mortality risk following TAVI compared to patients with an 
index $\geq 25 .^{74}$ Oversizing the prosthesis immediately after receiving TAVI has been shown to reduce paravalvular leakage and eliminate it in $52 \%$ of cases. ${ }^{75}$ However, over-dilation should be used judiciously as it can lead to annular rupture or cerebrovascular events. ${ }^{76,77}$ Overcoming these limitations would require the use of more accurate three-dimensional imaging methods such as computed tomography taken pre- and during procedures as well at follow-ups.

\section{Future TAVR}

Ten years experience have demonstrated the feasibility of a transcatheter aortic valve replacement in patients whose chance of survival following diagnosis of severe AS was poor without surgical replacement. The procedure has also opened up an array of other opportunities such as the possibility of carrying out a simultaneous percutaneous repair on mitral regurgitation or a coronary stent procedure with TAVR. The research in this field has also produced newer adjunct percutaneous products such as cerebral protection and sutureless transapical closure devices. Moreover, better use of imaging techniques would help reduce the incidence of patient-prosthesis mismatch (PPM) which may occur due to an incorrect determination of the annulus area. In addition to this, a better scoring system needs to be established that would avoid over-predicting mortality and the EuroSCORE II aims to address this. ${ }^{78}$ The future of TAVR may be particularly prominent in valve-in-valve procedures for older patients with a degenerated prosthesis but who may no longer be suitable for a repeat surgery.

Percutaneous hearts valves provide a promising alternative solution to valvular replacement in patients with severe AS who cannot undergo conventional surgery. Some of the complications of the earlier valves such as coronary ostia occlusion, paravalvular leaking and stent migration have been addressed in the next generation heart valves. However the later valve designs still have some way to go in developing a valve which will be able to survive long term implantation. The latest generation valves are still too large in patients with iliofemoral complications or those with smaller arteries, such as it is with children. It is envisaged that with the increased learning curve, improved materials leading to a reduction in stent and leaflet dimensions and smaller delivery catheters with greater flexibility can significantly reduce the incidence of stroke and vascular complications. 


\section{References}

1. Rao PS. Historical Aspects of Transcatheter Treatment of Heart Disease in Children. Pediat Therapeut. 2012; S5.

2. Andersen HR. History of Percutaneous Aortic Valve Prosthesis. Herz. 2009; 34: 343-6.

3. Moulopoulos SD, Anthopoulos L, Stamatelopoulos S and Stefadouros M. Catheter-Mounted Aortic Valves. The Annals of Thoracic Surgery. 1971; 11: 423-30.

4. Phillips SJ, Ciborski M, Freed PS, Cascade PN and Jaron D. A Temporary Catheter-Tip Aortic Valve: Hemodynamic Effects on Experimental Acute Aortic Insufficiency. The Annals of Thoracic Surgery. 1976; 21: 134-7.

5. Andersen HR, Knudsen LL and Hasenkam JM. Transluminal implantation of artificial heart valves. Description of a new expandable aortic valve and initial results with implantation by catheter technique in closed chest pigs. Eur Heart J. 1992; 13: 704-8.

6. Généreux P, Head SJ, Wood DA, et al. Transcatheter aortic valve implantation 10-year anniversary: review of current evidence and clinical implications. European Heart Journal. 2012.

7. Bourantas CV, van Mieghem NM, Farooq V, et al. Future perspectives in transcatheter aortic valve implantation. International Journal of Cardiology. 2013; 168: 11-8.

8. Reynolds MR, Magnuson EA, Lei Y, et al. Cost-Effectiveness of Transcatheter Aortic Valve Replacement Compared With Surgical Aortic Valve Replacement in High-Risk Patients With Severe Aortic Stenosis: Results of the PARTNER (Placement of Aortic Transcatheter Valves) Trial (Cohort A). Journal of the American College of Cardiology. 2012.

9. Pavcnik D, Wright KC and Wallace S. Development and Initial Experimental Evaluation of a Prosthetic Aortic-Valve for Transcatheter Placement - Work in Progress. Radiology. 1992; 183: 151-4.

10. Boudjemline Y and Bonhoeffer P. Steps Toward Percutaneous Aortic Valve Replacement. Circulation. 2002; 105: 775-8.

11. Boudjemline Y and Bonhoeffer P. Percutaneous implantation of a valve in the descending aorta in lambs. European Heart Journal. 2002; 23: 1045-9.

12. Lutter G, Kuklinski D, Berg G, et al. Percutaneous aortic valve replacement: An experimental study. I. Studies on implantation. Journal of Thoracic and Cardiovascular Surgery. 2002; 123: 768-76.

13. Paniagua D, Induni E, Ortiz C, Mejia C, Lopez-Jimenez F and Fish RD. Percutaneous Heart Valve in the Chronic In Vitro Testing Model. Circulation. 2002; 106: e51-e2.

14. Paniagua D, Condado JA, Besso J, et al. First human case of retrograde transcatheter implantation of an aortic valve prosthesis. Texas Heart Institute Journal. 2005; 32: 393.

15. Cribier A, Eltchaninoff $\mathrm{H}$, Bash A, et al. Percutaneous transcatheter implantation of an aortic valve prosthesis for calcific aortic stenosis - First human case description. Circulation. 2002; 106: 3006-8.

16. Cribier A, Eltchaninoff $\mathrm{H}$, Tron $\mathrm{C}$, et al. Early experience with percutaneous transcatheter implantation of heart valve prosthesis for the treatment of end-stage inoperable patients with calcific aortic stenosis. $J \mathrm{Am}$ Coll Cardiol. 2004; 43: 698-703.

17. Brodsky AM. Percutaneous approaches to aortic valve replacement. Cardiac Interventions. 2004: 4-9.

18. Webb JG and Binder RK. Transcatheter aortic valve implantation: The evolution of prostheses, delivery systems and approaches. Archives of Cardiovascular Diseases. 2012; 105: 153-9. 
19. Rodes-Cabau J. Transcatheter aortic valve implantation: current and future approaches. Nat Rev Cardiol. 2012; 9: 15-29.

20. Piazza N, Lange R, Martucci G and Serruys PW. Patient selection for transcatheter aortic valve implantation: Patient risk profile and anatomical selection criteria. Archives of Cardiovascular Diseases. 2012; 105: 165-73.

21. Grube E, Laborde JC, Zickmann B, et al. First report on a human percutaneous transluminal implantation of a self-expanding valve prosthesis for interventional treatment of aortic valve. Catheterization and Cardiovascular Interventions. 2005; 66: 465-9.

22. Grube E, Schuler G, Buellesfeld L, et al. Percutaneous Aortic Valve Replacement for Severe Aortic Stenosis in High-Risk Patients Using the Second- and Current Third-Generation Self-Expanding CoreValve Prosthesis: Device Success and 30-Day Clinical Outcome. J Am Coll Cardiol. 2007; 50: 69-76.

23. Grube E, Buellesfeld L, Mueller R, et al. Progress and Current Status of Percutaneous Aortic Valve Replacement: Results of Three Device Generations of the CoreValve Revalving System. Circulation: Cardiovascular Interventions. 2008; 1: 167-75.

24. Vahanian A, Himbert D, Brochet É, Depoix J-P, Iung B and Nataf P. Transcatheter aortic valve implantation: Our vision of the future. Archives of Cardiovascular Diseases. 2012; 105: 181-6.

25. Kalavrouziotis D, Li D, Buth KJ and Legare JF. The European System for Cardiac Operative Risk Evaluation (EuroSCORE) is not appropriate for withholding surgery in high-risk patients with aortic stenosis: a retrospective cohort study. Journal of cardiothoracic surgery. 2009; 4: 32.

26. Thomas M, Schymik G, Walther T, et al. One-Year Outcomes of Cohort 1 in the Edwards SAPIEN Aortic Bioprosthesis European Outcome (SOURCE) Registry: The European Registry of Transcatheter Aortic Valve Implantation Using the Edwards SAPIEN Valve. Circulation. 2011; 124: 425-33.

27. Lefèvre T, Kappetein AP, Wolner E, et al. One year follow-up of the multi-centre European PARTNER transcatheter heart valve study. European Heart Journal. 2011; 32: 148-57.

28. Antunes MJ. Editorial Comment: Aortic stenosis in octogenarians and other high-risk groups: what can surgical valve replacement offer? European Journal of Cardio-Thoracic Surgery. 2012; 42: 940-1.

29. Eltchaninoff H, Zajarias A, Tron C, et al. Transcatheter aortic valve implantation: technical aspects, results and indications. Archives of Cardiovascular Diseases. 2008; 101: 126-32.

30. Husser O, Rauch S, Endemann DH, et al. Impact of Three-Dimensional Transesophageal Echocardiography on Prosthesis Sizing for Transcatheter Aortic Valve Implantation. Catheterization and Cardiovascular Interventions. 2012; 80: 956-63.

31. Smith LA, Dworakowski R, Bhan A, et al. Real-Time Three-Dimensional Transesophageal Echocardiography Adds Value to Transcatheter Aortic Valve Implantation. Journal of the American Society of Echocardiography. 2013; 26: 359-69.

32. Ng ACT, Delgado V, van der Kley F, et al. Comparison of Aortic Root Dimensions and Geometries Before and After Transcatheter Aortic Valve Implantation by 2- and 3-Dimensional Transesophageal Echocardiography and Multislice Computed Tomography / CLINICAL PERSPECTIVE. Circulation: Cardiovascular Imaging. 2010; 3: 94-102.

33. Koos R, Altiok E, Mahnken AH, et al. Evaluation of aortic root for definition of prosthesis size by magnetic resonance imaging and cardiac computed tomography: Implications for transcatheter aortic valve implantation. International Journal of Cardiology. 2012; 158: 353-8.

34. Maeda K, Kuratani T, Torikai K, et al. Impact of Electrocardiogram-Gated Multi-Slice Computed Tomography-Based Aortic Annular Measurement in the Evaluation of Paravalvular Leakage Following Transcatheter Aortic Valve Replacement: The Efficacy of the OverSized AortiC Annular Ratio (OSACA Ratio) in TAVR. J Card Surg. 2013; 28: 373-9. 
35. Paniagua D, Condado JA, Besso J, et al. First human case of retrograde transcatheter implantation of an aortic valve prosthesis. Texas Heart Institute Journal. 2005; 32: 393.

36. Hanzel GS, Harrity PJ, Schreiber TL and O'Neill WW. Retrograde percutaneous aortic valve implantation for critical aortic stenosis. Catheterization and Cardiovascular Interventions. 2005; 64: 322-6.

37. Webb JG, Chandavimol M, Thompson CR, et al. Percutaneous Aortic Valve Implantation Retrograde From the Femoral Artery. Circulation. 2006; 113: 842-50.

38. Chiam PTL and Ruiz CE. Percutaneous transcatheter aortic valve implantation: Evolution of the technology. American Heart Journal. 2009; 157: 229-42.

39. Willson A, Toggweiler S and Webb JG. Transfemoral aortic valve replacement with the SAPIEN XT valve: step-by-step. Seminars in Thoracic and Cardiovascular Surgery. Elsevier, 2011, p. 51-4.

40. Sandgren T, Sonesson B, Ahlgren AR and Lanne T. The diameter of the common femoral artery in healthy human: Influence of sex, age, and body size. Journal of Vascular Surgery. 1999; 29: 503-10.

41. Lichtenstein SV, Cheung A, Ye J, et al. Transapical transcatheter aortic valve implantation in humans Initial clinical experience. Circulation. 2006; 114: 591-6.

42. Walther T, Möllmann H, Linden Av and Kempfert J. Transcatheter Aortic Valve Implantation Transapical: Step by Step. Seminars in thoracic and cardiovascular surgery. 2011; 23: 55-61.

43. Ye J, Cheung A, Lichtenstein SV, et al. Transapical transcatheter aortic valve implantation: follow-up to 3 years. The Journal of thoracic and cardiovascular surgery. 2010; 139: 1107-13, 13.e1.

44. Kempfert J, Rastan A, Holzhey D, et al. Transapical Aortic Valve Implantation. Analysis of Risk Factors and Learning Experience in 299 Patients. Circulation. 2011; 124: S124-S9.

45. Thomas M, Schymik G, Walther T, et al. One-Year Outcomes of Cohort 1 in the Edwards SAPIEN Aortic Bioprosthesis European Outcome (SOURCE) Registry / Clinical Perspective. Circulation. 2011; 124: 425-33.

46. Kempfert J, Rastan AJ, Beyersdorf F, et al. Trans-apical aortic valve implantation using a new selfexpandable bioprosthesis: initial outcomes. European Journal of Cardio-Thoracic Surgery. 2011; 40: 1114-9.

47. Kempfert J, Treede H, Rastan AJ, et al. Transapical aortic valve implantation using a new selfexpandable bioprosthesis (ACURATE TA((TM))): 6-month outcomes(dagger). European Journal of CardioThoracic Surgery. 2013; 43: 52-7.

48. Sinning JM, Werner N, Nickenig G and Grube E. Next-generation transcatheter heart valves: current trials in Europe and the US. Methodist Debakey Cardiovasc J. 2012; 8: 9-12.

49. Buellesfeld L, Gerckens U and Grube E. Percutaneous implantation of the first repositionable aortic valve prosthesis in a patient with severe aortic stenosis. Catheterization and Cardiovascular Interventions. 2008; 71: 579-84.

50. Bolling SF, Rogers JH, Babaliaros V, et al. Percutaneous aortic valve implantation utilising a novel tissue valve: preclinical experience. EuroIntervention. 2008; 4: 148-53.

51. Low RI, Bolling SF, Yeo KK and Ebner A. Direct flow medical percutaneous aortic valve: proof of concept. EuroIntervention. 2008; 4: 256-61.

52. Bijuklic K, Tuebler T, Reichenspurner H, et al. Midterm stability and hemodynamic performance of a transfemorally implantable nonmetallic, retrievable, and repositionable aortic valve in patients with severe aortic stenosis. Up to 2-year follow-up of the direct-flow medical valve: a pilot study. Circulation Cardiovascular interventions. 2011; 4: 595-601.

53. Krumsdorf U, Bekeredjian R, Korosoglou G, et al. Percutaneous Aortic "Valve in Valve" Implantation for Severe Aortic Regurgitation in a Degenerated Bioprosthesis. Circulation: Cardiovascular Interventions. 2010; 3: e6-e7. 
54. Webb JG, Wood DA, Ye J, et al. Transcatheter Valve-in-Valve Implantation for Failed Bioprosthetic Heart Valves. Circulation. 2010; 121: 1848-57.

55. Ruiz CE, Laborde JC, Condado JF, Chiam PTL and Condado JA. First percutaneous transcatheter aortic valve-in-valve implant with three year follow-up. Catheterization and Cardiovascular Interventions. 2008; 72: 143-8.

56. Tarantini G, Gasparetto V, Napodano M, Fraccaro C, Gerosa G and Isabella G. Valvular leak after transcatheter aortic valve implantation: a clinician update on epidemiology, pathophysiology and clinical implications. American journal of cardiovascular disease. 2011; 1: 312-20.

57. Smith CR, Leon MB, Mack MJ, et al. Transcatheter versus Surgical Aortic-Valve Replacement in High-Risk Patients. New England Journal of Medicine. 2011; 364: 2187-98.

58. Leon MB, Smith CR, Mack M, et al. Transcatheter Aortic-Valve Implantation for Aortic Stenosis in Patients Who Cannot Undergo Surgery. New England Journal of Medicine. 2010; 363: 1597-607.

59. Kodali SK, Williams MR, Smith CR, et al. Two-Year Outcomes after Transcatheter or Surgical AorticValve Replacement. New England Journal of Medicine. 2012; 366: 1686-95.

60. Makkar RR, Fontana GP, Jilaihawi H, et al. Transcatheter Aortic-Valve Replacement for Inoperable Severe Aortic Stenosis. New England Journal of Medicine. 2012; 366: 1696-704.

61. Kahlert P, Knipp SC, Schlamann M, et al. Silent and Apparent Cerebral Ischemia After Percutaneous Transfemoral Aortic Valve Implantation. Circulation. 2010; 121: 870-8.

62. Holmes Jr DR, Mack MJ, Kaul S, et al. 2012 ACCF/AATS/SCAI/STS Expert Consensus Document on Transcatheter Aortic Valve Replacement. Journal of the American College of Cardiology. 2012; 59: 1200-54.

63. Cao C, Ang SC, Indraratna P, et al. Systematic review and meta-analysis of transcatheter aortic valve implantation versus surgical aortic valve replacement for severe aortic stenosis. Annals of Cardiothoracic Surgery. 2013; 2: 10-23.

64. Vahanian A, Alfieri O, Al-Attar N, et al. Transcatheter valve implantation for patients with aortic stenosis: a position statement from the European Association of Cardio-Thoracic Surgery (EACTS) and the European Society of Cardiology (ESC), in collaboration with the European Association of Percutaneous Cardiovascular Interventions (EAPCI). European Heart Journal. 2008; 29: 1463-70.

65. Khawaja MZ, Rajani R, Cook A, et al. Permanent pacemaker insertion after CoreValve transcatheter aortic valve implantation: incidence and contributing factors (the UK CoreValve Collaborative). Circulation. 2011; 123: 951-60.

66. Chieffo A, Buchanan GL, Van Mieghem NM, et al. Transcatheter Aortic Valve Implantation With the Edwards SAPIEN Versus the Medtronic CoreValve Revalving System DevicesA Multicenter Collaborative Study: The PRAGMATIC Plus Initiative (Pooled-RotterdAm-Milano-Toulouse In Collaboration). Journal of the American College of Cardiology. 2013; 61: 830-6.

67. Rubín JM, Avanzas P, del Valle R, et al. Atrioventricular Conduction Disturbance Characterization in Transcatheter Aortic Valve Implantation With the CoreValve Prosthesis. Circulation: Cardiovascular Interventions. 2011; 4: 280-6.

68. Toggweiler S, Gurvitch R, Leipsic J, et al. Percutaneous Aortic Valve Replacement: Vascular Outcomes With a Fully Percutaneous Procedure. Journal of the American College of Cardiology. 2012; 59: 1138 .

69. Grube E, Naber C, Abizaid A, et al. Feasibility of Transcatheter Aortic Valve Implantation Without Balloon Pre-DilationA Pilot Study. JACC: Cardiovascular Interventions. 2011; 4: 751-7.

70. Bleiziffer S, Mazzitelli D, Nöbauer C, Ried T and Lange R. Successful Treatment of Pure Aortic Insufficiency with Transapical Implantation of the JenaValve. Thorac cardiovasc Surg. 2013; 61: 428-30. 
71. Seiffert M, Diemert P, Koschyk D, et al. Transapical Implantation of a Second-Generation Transcatheter Heart Valve in Patients With Noncalcified Aortic Regurgitation. JACC: Cardiovascular Interventions. 2013; 6: 590-7.

72. Moat NE, Ludman P, de Belder MA, et al. Long-Term Outcomes After Transcatheter Aortic Valve Implantation in High-Risk Patients With Severe Aortic StenosisThe U.K. TAVI (United Kingdom Transcatheter Aortic Valve Implantation) Registry. Journal of the American College of Cardiology. 2011; 58: 2130-8.

73. Tamburino C, Capodanno D, Ramondo A, et al. Incidence and Predictors of Early and Late Mortality After Transcatheter Aortic Valve Implantation in 663 Patients With Severe Aortic Stenosis. Circulation. 2011; 123: 299-308.

74. Sinning J-M, Hammerstingl C, Vasa-Nicotera M, et al. Aortic Regurgitation Index Defines Severity of Peri-Prosthetic Regurgitation and Predicts Outcome in Patients After Transcatheter Aortic Valve Implantation. Journal of the American College of Cardiology. 2012; 59: 1134-41.

75. Unbehaun A, Pasic M, Dreysse S, et al. Transapical Aortic Valve ImplantationIncidence and Predictors of Paravalvular Leakage and Transvalvular Regurgitation in a Series of 358 Patients. Journal of the American College of Cardiology. 2012; 59: 211-21.

76. Barbanti M, Yang T-H, Rodés-Cabau J, et al. Anatomical and Procedural Features Associated with Aortic Root Rupture During Balloon-Expandable Transcatheter Aortic Valve Replacement. Circulation. 2013.

77. Nombela-Franco L, Rodés-Cabau J, DeLarochellière R, et al. Predictive Factors, Efficacy, and Safety of Balloon Post-Dilation After Transcatheter Aortic Valve Implantation With a Balloon-Expandable Valve. JACC: Cardiovascular Interventions. 2012; 5: 499-512.

78. Nashef SA, Roques F, Sharples LD, et al. EuroSCORE II. Eur J Cardiothorac Surg. 2012; 41: 734-44; discussion 44-5. 